\title{
LONDON REVIEW OF EDUCATION
}

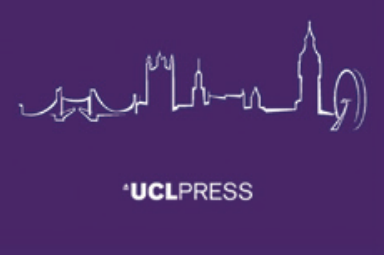

e-ISSN: $1474-8479$

Journal homepage:

https://www.uclpress.co.uk/pages/london-review-ofeducation

\section{Artificial intelligence and the technological turn of public education privatization: In defence of democratic education}

Kenneth J. Saltman iD

\section{How to cite this article}

Saltman, K.J. (2020) 'Artificial intelligence and the technological turn of public education privatization: In defence of democratic education'. London Review of Education, 18 (2): 196-208. https://doi.org/10.14324/LRE.18.2.04

Submission date: 1 October 2019

Acceptance date: 10 February 2020

Publication date: 21 July 2020

\section{Peer review}

This article has been peer-reviewed through the journal's standard double-blind peer review, where both the reviewers and authors are anonymized during review.

\section{Copyright}

(C) 2020 Saltman. This is an Open Access article distributed under the terms of the Creative Commons Attribution Licence (CC BY) 4.0 https://creativecommons.org/licenses/by/4.0/, which permits unrestricted use, distribution and reproduction in any medium, provided the original author and source are credited.

\section{Open access}

London Review of Education is a peer-reviewed Open Access journal. 


\title{
Artificial intelligence and the technological turn of public education privatization: In defence of democratic education
}

\author{
Kenneth J. Saltman* - University of Illinois at Chicago, USA
}

\begin{abstract}
This article considers how the development of for-profit artificial intelligence (Al) technologies fosters the privatization of public education and erodes the values and practices of democratic education. The introduction situates the advent of digital technologies in the context of the structural economic and ideological shifts of the past 40 years. Such changes include neo-liberal restructuring, the repressive school and social turn, changes in the use of positivist ideology in schooling, the role of new technologies in social and cultural reproduction and changing imperatives for capital accumulation. The article illustrates different uses of $\mathrm{Al}$ as part of the technological turn of public education privatization. Examples include: (1) adaptive learning technology, and transformations to teacher work and conceptions of knowledge and learning; (2) biometric pedagogy and the cultural politics of locating learning in the body; and (3) the convergence of impact investing and digital surveillance technologies. The article considers how changes in the ownership and control over different aspects of public education relate to the cultural politics of knowledge and learning. It also examines how, under the guise of disinterested objectivity and neutrality, particular class and cultural ideologies and interests are promoted through new technologies, with significant pedagogical, cultural, economic and political implications. The article concludes by arguing that $\mathrm{Al}$ education is a site of cultural and political contestation and must be comprehended as a form of representational politics. By showing a critical pedagogical Al project, the article suggests that the anti-democratic tendencies of most Al education is hardly inevitable or determined, but rather represents a replication of long-standing ideologies.
\end{abstract}

Keywords: artificial intelligence, democratic education, adaptive learning, social impact bonds, critical pedagogy

\section{Introduction}

Contemporary concerns about the nefarious tendencies of artificial intelligence (Al) technology have become widespread in public and popular cultural discourse. These range from anxiety about Al coming to consciousness, usurping human control over other machines and infrastructure and annihilating humanity (The Terminator, Ex Machina, Elon Musk); to Al's uses in automating inequality (Eubanks, 2017; O'Neil, 2016) in public service agencies to conceal austerity agendas that target the poor; to concerns about surveillance capitalism (Zuboff, 2019) that eradicates privacy while translating human experience into behavioural data that forms the basis for prediction products and behavioural futures markets. While many of these fears are warranted, a great deal of the fear of Al applications depends upon a false assumption that the 
technology has a kind of mystical transcendent agency that evades human capacities for governing it. Rather, the ways that the technology is being implemented in education illustrate long-standing economic, political and ideological agendas and interests (Selwyn, 2019: 22). The positioning of the technology as an autonomous force delinked from human control conceals the material and symbolic interests served by the technology. The strategic erasure of human agency obscures the very specific and intentional uses of the technology. What is more, as I discuss below, the misrepresentation of data as delinked from culture and politics, as allegedly disinterested and neutral, obscures the inevitable political and ethical norms and values that particular education projects, including Al education, animate and enact.

This article argues that the development of for-profit Al technologies largely fosters the privatization of public education and the concomitant erosion of the values and practices of public and critical forms of democratic education. In what follows, I situate the advent of digital technologies in the context of the structural economic and ideological shifts of the past 40 years. Such changes include neo-liberal restructuring, the repressive school and social turn, changes in the use of positivist ideology in schooling, the role of new technologies in social and cultural reproduction and changing imperatives for capital accumulation. Sections of the article illustrate different uses of $\mathrm{Al}$ as part of the technological turn of public education privatization and consider Al in relation to the broader structural and ideological context. I consider the ways in which Al continues long-standing trends through the promotion of: adaptive learning technology and transformations of teacher work and conceptions of knowledge and learning; biometric pedagogy and the cultural politics of locating learning in the body; and the convergence of impact investing and digital surveillance technologies. Changes in the ownership and control over different aspects of public education relate to the cultural politics of knowledge and learning.

In what follows, I first review three significant Al applications in education: adaptive learning technology, biometric pedagogy and the intersection of social impact bonds/pay for success with digital surveillance. The sections that follow take up these Al education examples in relation to the longer-standing legacies of neoliberal privatization, repression and positivism for social and cultural reproduction. The sections consider how the uses of Al continue and break with prior trends and tendencies. The article concludes by considering how and what place there might be for values of democratic education in the uses of these new technologies. By illustrating the democratic possibilities of an Al education project, the conclusion emphasizes that the social and ethical implications of the technology itself are not fixed or determined.

\section{Al education}

According to the 2016 White House report Preparing for the Future of Artificial Intelligence, 'a core objective of Al research and applications over the years has been to automate or replicate intelligent behaviour' (NSTC, 2016: 7). In education, numerous companies pursue narrow $\mathrm{Al}$, rather than general $\mathrm{Al}$ that aspires to automated general intelligence and machine autonomy. Narrow Al, which attempts to outperform humans in a particular task, 'underpins many commercial services such as trip planning, shopper recommendation systems, and ad targeting, and is finding important applications in medical diagnosis, education, and scientific research' (ibid.). In analysing test, textbook and media giant corporation Pearson's Al projects, Williamson et al. (2018) report a number of Al projects underway. These include 'data analytics techniques, machine learning algorithms, computer modelling, statistics, artificial neural networks 
and neuroscience' (ibid.: 11). Some of the most significant Al projects involve for-profit educational endeavours that push profit seeking into schooling in relatively new ways.

For-profit Al education companies and for-profit education businesses are coming together. Corporate media is converging with corporate education sectors as large media corporations such as Apple, Microsoft, Chan Zuckerberg Initiative (Facebook) and Alphabet (Google) have become major for-profit education companies, and traditional educational test and textbook purveyors such as Pearson NCS, Houghton Mifflin, McGraw-Hill and Wiley Education have increasingly become media corporations (Saltman, 2017: 74-95). Also, long-standing for-profit educational contractors have moved into Al. For example, Knewton (acquired by Wiley Education in 2019) was spun-off from Edison Learning, one of the largest for-profit educational management organizations. Collectively, such for-profit corporations have shifted ownership, design and control of curriculum and pedagogical practice from teachers to business. Bolstering a neo-liberal ideology that positions public education as business and in the service of business, ideologies of techno-utopian progress, technological disruptions and the equation of technology with economic growth have played a large part in the rapid and exponential growth of digital technology in schools (Means, 2018: 6).

Despite the prevalence of techno-utopian ideology, some of the actual applications have ranged from the questionable and ineffectual to the outright embarrassing. For example, in Los Angeles, billions of dollars were spent on tablets that did not work, and young children were found to be drawing on them with crayons. No empirical evidence exists to support the success of Al applications of adaptive learning technology in traditional measures of test-based achievement (Boninger et al., 2019: 10; Pane, 2018: 4). Beyond the ways in which unproven technology displaces sound educational practice, the usurpation of pedagogy and curriculum has significant implications for how people understand the relationships between learning and the self, knowledge and the social context, and the roles and purposes of schools. Techno-utopianism is thoroughly wrapped up with what has become the dominant justification for schooling - the means for youth to be workers and consumers, and the means for nations to compete in the global economy. Learning as the means of social and political agency and democratic self-governance has been crowded out of the education technology discourse. Indeed, at the time when, according to tech leaders Mark Zuckerberg, Elon Musk and Bill Gates, futures for capitalism, the environment and work itself are increasingly called into question by technological development, and more specifically Al, the ideologies of technological utopianism and determinism are ubiquitous in public and policy discourse (Žižek, 2018: 14).

Some of the most prevalent for-profit endeavours of $\mathrm{Al}$ in education involve producing student data that is then sold, contracting with public entities to get forprofit technologies into schools, and making behaviour and body management and influence into data products (Boninger et al., 2019; Sadowski, 2019; Manolev et al., 2019). These initiatives collapse the distinction between for-profit private industries and nonprofit public entities. Three such projects are adaptive learning technology, biometric pedagogy technology and the quantification of impact investing schemes through machine learning. These three projects exemplify the ways in which Al in education allows for expanded privatization, contracting and labour expropriation, while undermining the democratic culture and possibilities of schooling as a means for the broader democratization of society. I summarize the technologies here first, and then discuss them together in terms of the key concerns with economic exploitation, the dedemocratization of schooling and the legacies of prior forms of educational privatization. 


\section{Adaptive learning technology}

Chan Zuckerberg Initiative's (CZI) adaptive learning technology platform Summit exemplifies the varieties of profit seeking in technology. While Summit offers school districts its basic program for free, the fuller implementation requires payment. Summit is part of a limited liability company, CZI, which includes for-profit pay-for-fee educational services such as BYJU'S and other for-profits that were acquired exclusively for capturing user data. The limited liability company structure makes the movement of money, not to mention data, between these subunits secret and unaccountable to public oversight. Summit was developed by Facebook engineers and, while Summit does not have advertisements, it is, like Facebook, a data production engine. A major concern about adaptive learning technology in education involves the ways in which it appropriates private data about youth:

Like Summit, Canvas connects children to third-party sites (such as YouTube) that collects data for advertising purposes, and it denies responsibility for any use a third party might make of children's or teachers' data. Companies may share aggregated and de-identified data without notice to users, despite evidence that such de-identified data is easily reidentified. (Boninger et al., 2019: 21)

Roberts-Mahoney et al. (2016) liken adaptive learning to the 'Netflixing' of education. Purporting to be 'personalized', adaptive learning technology tailors content or the pace of delivery to students. Proponents of adaptive learning technology claim that their products individualize instruction, and are attentive to individual needs, pace and capacity, and hence overcome pedagogical standardization, homogenized curriculum and excessive testing. Mainstream criticism of adaptive learning technology points out that evidence does not exist for its efficacy as measured by standardized test scores (Boninger et al., 2019: 10), and that it represents a form of privatization and commercialism by shifting control over curriculum and pedagogy from teachers and schools to for-profit corporations.

Under the rubric of 'personalization', adaptive learning programs undermine genuine personalization by delinking knowledge and learning from the subjectivities, differences and experiences of particular students and their cultures and communities (Saltman, 2018: 53-74). These programs also prevent the student from comprehending themselves as socially formed and from comprehending knowledge as a source of social and political agency. Adaptive learning technologies create the conditions for student activity to be collected as data, and for this collected data to be bought and sold and financialized as investment securities, regardless of whether the student advances. That is, adaptive learning technology stands to revive and deepen long-standing tracking, sorting and sifting of students based on alleged ability. While proponents of adaptive learning technology claim to reduce testing, the technology and curriculum have been developed around constant testing and teaching to the tests. The tests are misframed as conveying universally valuable, disinterested and objective knowledge. As such, the constant testing accomplishes what standardized tests typically do. Namely, the tests obscure the cultural politics of knowledge that informs the selection of knowledge to be taught and circumscribes the range of possible interpretations and interpretive frameworks for claims to truth. The tests prohibit an approach to knowledge in which students comprehend claims to truth in relation to material and symbolic antagonisms, interests, ideologies and social positions. Adaptive learning technology pushes standardized and transmission-oriented approaches to teaching that rely upon the promise of technological innovation and the ideology of corporate culture as a 
justification. The standardization and homogenization of knowledge and curriculum, and the treatment of knowledge as a consumable commodity, promotes a particular conception of the relationship between knowledge and agency. Knowledge appears as something made by others with authority elsewhere, to consume and regurgitate, rather than as something discovered and produced through dialogic exchange. Knowledge does not appear to students as a means to interpret experience and the social world so as to act on and shape that world. The pedagogies of adaptive learning technology stand in stark contrast to, for example, critical pedagogies that foster deliberation, debate and dissent, and investigation of the relationships between claims to truth and the interests, authority and social positions of those who make the claims.

CZI misrepresents itself as philanthropy, when it largely operates as a business. Due to its limited liability company corporate structure, CZI muddles for-profit and nonprofit subsidiaries, moves money secretly, refuses public oversight and accountability, and operates as a for-profit business running pay-for-fee services, grabbing student data that it commodifies from its 'free services' (ibid.: 53-74). CZI and other philanthrocapitalists, such as Emerson Initiative and Omidyar Network, collectively mark a significant shift in philanthropy from the still-large venture philanthropy mode. Venture philanthropists such as Gates, Walton and Broad are non-profit foundations that promote a neo-liberal agenda of educational privatization and the imposition of corporate managerial culture in school leadership (Saltman, 2010). Venture philanthropists have facilitated the usurpation of educational and policy governance over education by super-rich individuals and corporations. Philanthrocapitalists erode the distinction between public and private altogether within their organizations, eliding the difference between private interest and public good.

\section{Biometric pedagogy}

As I detailed in Scripted Bodies (Saltman, 2017: 55-73), biometric analytic pedagogy uses Al technology to teach by measuring bodies. Some systems utilize skin-sensing bracelets, while others employ webcam video cameras connected to software platforms that analyse changes to students' bodies in response to a lesson. Based on consumer marketing feedback devices, webcam systems such as Affdex measure positive and negative valence and attention to the teacher. Biometric pedagogy devices make physical movements into data and correlate body movements to presumed internal cognitive and emotional reactions, which are presumed to be reactions to the teacher's behaviour. These data then become the basis for the evaluation of the efficacy of the teacher, and the learning of the student, and are supposed to be able to inform the teacher's pedagogical responses in real time. Machine learning is involved in recognition and comparison of physical movements.

Biometric pedagogy devices presume that learning is the result not of the dialogue-based exchange between teacher and students, but rather of the successful impact of the teacher on the student as measured by the student's body. The body as measure of learning, and the equation of physical dispositions with learning, displaces not only traditional conceptions of learning through dialogic exchange; it also displaces questioning and thinking, and the recognition that students mediate or resist what they learn in sometimes contradictory ways. While dialogue offers ways for students and teachers to work through those contradictions, biometric pedagogy does not. Biometric pedagogy presumes a direct, transparent and simplistic notion of learning as the depositing of knowledge. The uses of biometric pedagogy are similar to the teacher clinical practice assessment system edTPA that treats teaching as a scripted performance that aims to elicit a particular physical response from students, 
which may or may not correlate with learning. Biometric pedagogy revives behaviourist and Taylorist approaches to labour aimed at breaking down the tasks and subtasks of workers to make them ever more approximate a continually raised targeted norm prescribed from the outset. Such prescription fosters an approach to teaching that denies the subjectivities of learners, the particular context for learning and the broader social structures, systems and forces that inform the meaning of knowledge and the interpretive acts of teaching and learning.

\section{Pay for success and social impact bonds}

Pay for success or social impact bonds (SIBs) are not themselves Al technologies. Pay for success utilizes digital surveillance technology and has been increasingly merging with Al applications for targeting potential victims/beneficiaries of SIB services, pricing of services, automation of services and risk profiling of students. Aleron social impact consultancy (https://aleronpartners.com) typifies this convergence. Social impact bonds are privatization investment schemes that have, since about 2010, rapidly expanded in size, scope and reach of implementation (Saltman, 2018: 25-42). As I detail in The Swindle of Innovative Educational Finance, SIBs partner investment banks such as Goldman Sachs with governmental bodies such as the city of Chicago or the state of Massachusetts and are facilitated by non-profit foundations such as Rockefeller. SIBs identify programmes, such as a juvenile justice recidivism reduction programme or an early childhood education programme, to be funded by the investment bank and to be evaluated for efficacy by an allegedly independent evaluator. The investor pays for the service, and if the metrics suggest the service was a success, then the public repays the investor much more money than it would have cost the public to pay for the service directly. For example, Goldman Sachs doubled its money by funding a successful early childhood education project (ibid.: 25). However, Goldman Sachs selected that longrunning programme because it was already a proven success. In its Massachusetts recidivism reduction project, Goldman Sachs employees lobbied juvenile justice workers to attempt to influence the 'independent' assessment of success (ibid.: 33). Pay for success should be seen largely as a way for private investors to inflate and skim costs of services, driving money out of public coffers and into investment banks, while providing lots of well-paying professional-class jobs to those in non-profits, philanthropies and universities (such as Harvard), who help to put these deals together.

While the websites and press releases of the social impact industry, such as the UBS bank and the rock star Bono, are effusively celebratory of the convergence of social impact and Al, others see trouble. Alyson McDowell, a scholar and activist with a widely influential technology and society blog, Wrench in the Gears (2019: n.p.), has been warning about the dangers of the convergence of impact investing and digital technology:

'Pay for success' was embedded into federal education law with the passage of the Every Student Succeeds Act. Public-private partnerships, in coordination with investors, are embracing this form of 'innovative finance,' catalyzing new markets in human capital. Digital platforms, including edtech and online behavioral services, are designed to generate data for the evaluation of outcomes-based contracts. That is what is behind the push for expanded screen-time and benchmark testing in schools ... Children are being turned into data so the debt associated with funds allocated to provide education and social services to them can be traded on global markets (like bundled mortgages prior to the 2008 crash). 
McDowell's warning needs to be taken seriously as the varieties of Al education schemes stand to completely displace the humanistic, social and democratic potential of public education in favour of making students into captured data engines, while those students are put on rigid tracks for the future by the very information they are compelled to produce.

\section{Al privatization in the context of neo-liberal privatization, de-democratization and the legacies of positivism}

The means of profit through corporeal control expanded radically in the neo-liberal era. The for-profit control of bodies ranges from the multibillion dollar test and textbook standardization craze to the connected multibillion dollar business in drugging students into test performance and attention with ADHD medications, the massive growth of security apparatus, school militarization and prisonization and the boom in contracting out the management of schools to corporations facilitated through the charter movement. The turn to the body and its control has expanded since the 2000s, with a focus on behaviourist social emotional learning and grit pedagogies, particularly promoted through rigid control-oriented private school contractors such as KIPP and Edison Learning, which seek to standardize knowledge, and the time and space of school. Old and new forms of social and cultural reproduction, and the turn to the body, created the conditions for the particular forms of privatization through digital technology.

Al technologies continue and deepen the repressive and corporeal control trends in neo-liberal education. Biometric pedagogy presumes that teaching aims to produce a biological effect that can be measured on the body and its behaviours. In this case, physical response stands in for attention and learning. Teaching becomes a performance that is measured for its impact on the body of the student. Biometric pedagogy uses cutting edge technology for real-time data analytics that are supposed to provide the teacher with information about whether students are paying attention, or exhibit a positive valence towards a lesson. However, biometric pedagogy is radically regressive, dredging up early twentieth-century models of scientific management and Taylorism that aimed for ever-greater amounts of physical measurement of labour and sub-tasks. Such measurement aims for ever-greater control over the worker's body.

Indeed, it is not a coincidence that biometric surveillance and 'nudging' technologies are being implemented in warehouses and factories and schools. A major casualty of such technologies is the displacement of teaching and learning oriented around dialogue, interpretation and judgement. Instead, teaching is conceived as a means of knowledge transfer, with the technology facilitating ever-greater efficiencies of delivery. As Williamson and Piattoeva (2019: 74) point out, the biometric pedagogy trend is wrapped up with the making of social emotional learning into measurable quantifiable behaviours that are correlated to market capacities of subjects as future workers. Here I see the uses of Al in the making of market-based subjectivity, and the development of quantification of representations of subjectivity. Adaptive learning, despite being widely promoted as personalized, tends to delink learning from student and teacher subjectivities and particular contexts, as well as from the broader social context. In their stead, adaptive learning builds standardization, homogenization and constant testing into the curriculum and pedagogy. Moreover, adaptive learning appears to be developing towards a kind of techno-tracking - making a longitudinal case out of the student, interpellating the student through technology use practices into a good or bad, efficacious or failed, student for whom the implicit 
values, ideologies and messages of the curriculum are beyond question and debate. Such techno-tracking stands to sort and sift students under a false guise of individualized teaching - rewarding the cultural capital (Bourdieu, 1986) of culturally and class-dominant students, and punishing the cultural capital of culturally and classsubordinate students. These technologies in their current implementations are largely repeating and deepening the worst aspects of standardized testing, its refusal of the cultural politics of knowledge and its mistaken framing of test scores as learning. The tendencies are deeply anti-democratic in that they treat knowledge as a consumable commodity rather than as being subject to contestation, while undermining learning as the basis for social and political agency. They falsely frame knowledge and school as apolitical.

It is not a coincidence that the profit-seeking activities of privatizers are antidemocratic. In order to extract profit, businesses impose hierarchical controls even at the expense of productivity (Bowles and Gintis, 2011: 79). In the case of educational privatization, the standardization and homogenization of curriculum, pedagogical approaches and school models aim to maximize the possibilities of profit through 'economies of scale', and by automating and displacing the most expensive element of schooling: teacher labour. While this tendency for standardization and homogenization of knowledge has been particularly common with for-profit educational management organizations such as Edison Learning, saving money by using mass-produced curricula, it continues with Al. For example, despite the appropriation of the language of 'personalized learning', adaptive learning companies use homogeneous curricula and homogeneous regular tests with automated adjustment to the pace of delivery. Adaptive learning decontextualizes learning from the subjective experiences of students and the particular cultural knowledge they bring to the learning encounter. Similarly, biometric pedagogy devices aim to measure impact of delivery of a standardized lesson. Privatization also captures the uses of public institutions for private sector uses and imposes corporate managerial models that assure that the external private uses of state schools are the priority for state schools over other uses that might directly serve the public interest. A glaring instance of this is the way that basic skills and disciplinary agenda for low-paid, low-skilled workers are imposed on the schools of working-class and poor communities rather than intellectual and socially engaged forms of teaching that treat knowledge as a form of social agency and instrument for self-governance. The ideologies of corporate culture could not be more apparent than in the case of Mark Zuckerberg's and Summit CEO Dianne Tavenner's description of Summit: here, they celebrate students working on their laptops around a table: 'According to Zuckerberg, "it feels like the future - it feels like a start up." And says Tavenner, "It looks more like Google or Facebook than a school"' (Singer, 2017: A1). Meanwhile, in the places that Summit has been most widely implemented, such as Providence, Rhode Island, the technology appears not to feel much like 'a start up' and 'the future' to teachers, administrators and students, who resent excessive screenfocused schooling and 'almost universally dislike it', feeling bored and burned out according to an external review of the district by Johns Hopkins University researchers (Kronk, 2019). They also found that students skipped through lessons to guess through tests, and that the technology undermined collective and individual lessons (ibid.). Although it is hard to discern that students are learning from their activities, they are nonetheless producing commercially valuable data in their compulsory attendance.

The repressive and deeply anti-democratic tendencies of the neo-liberal era described in Saltman (2017: 1-17) mark a significant break with the way that public education was implicated in reproducing the social and cultural conditions for capital 
accumulation in the industrial era. As Bowles and Gintis (2011) detail, in the industrial economy, state schools largely taught class-based knowledge, skills and dispositions for students to take their prescribed places in the economy as workers or managers. Students learned not just skills and know-how for work, but also the ideologies and social relations for them to become sufficiently docile and obedient workers or collaborative and authoritative leaders. Industrial era social and cultural reproduction represented a long-term investment in creating the conditions for workers' labour to be profitable for owners. These conditions included time- and labour-intensive learned self-regulation of workers. In the neo-liberal era, the offshoring of production, deindustrialization, the shift from the industrial to the financial and service economy and the end of the grand bargain between capital and labour, resulted in a revision of social and cultural reproduction. Social and cultural reproduction in the post-Fordist neo-liberal era relies less and less on disciplinary power - that is, learned self-regulation - and more and more on direct control of bodies. Profits in the post-industrial neo-liberal economy rely less on long-term investments in making subjects equipped with the knowledge and dispositions for exploitable work. Increasingly, the body and its activity itself becomes a commodity that facilitates contracting profits. From for-profit prisons to for-profit schools, control of bodies becomes a lucrative means for capital accumulation. In this context, the time- and labour-intensive forms of self and social control give way to direct coercive technologies. The process of psychological therapy gives way to the behaviour control pill. The rehabilitative prison gives way to warehousing in for-profit prisons. School for work gives way to school for contracting.

Part of what is new with the measurement and control over the body through biometrics, adaptive learning and SIBs is the use of the students' bodies as engines of data production. As Sadowski (2019: 2) points out, data is capital, and digital technology producers aim to capture as much data as possible for potential future use through big data applications. Long-standing school commercialism, such as advertising in textbooks, aims to take advantage of students as a captive audience that is particularly vulnerable to the messages and imprints of corporations hoping to make loyal lifelong consumers. Al education platforms function more akin to what mass communications theorist Dallas Smythe (1981) described in relation to advertising-driven broadcast television. Smythe (ibid.: 22-51) explained that television advertisements compel the viewer to do the uncompensated educative labour of learning about products and learning social relations conducing to the reproduction of capital. Al education puts youth to work using applications to create enormous quantities of data about the user, the group of users and the institution. All of that data that youth produce has a commercial value that is extracted by the digital technology company while the data producer is uncompensated. A democratic approach to the ownership and control over data would insist on data makers retaining ownership rights to the data that they produce and reaping any financial benefits to such activity, either individually or collectively. A more deeply democratic approach to data would be to recognize that the very concept of data is educationally problematic in that it denies the values, assumptions and ideologies informing the data, and it also denies the values, assumptions and ideologies of the person interpreting the meaning of data.

Sadowski (2019: 2) points out that data is not 'mined' but rather manufactured, 'a recorded abstraction of the world created and valorised by people using technology'. As Sadowski (2019) observes, data has become akin to financial capital and is itself a form of capital. Corporations are collecting data first in order to later figure out what to do with it for profit. What is so troubling about this is that the values and assumptions of data collection are unexamined. The values, assumptions and ideologies undergirding 
the design of data collection algorithms are delinked from the data that the use of said algorithms manufacture. Most users lack the technical coding skill, let alone the cultural theory, to deconstruct the Al education platform and recontextualize the data they produce in terms of broader economic, political and cultural systems, structures and forces.

Sadowski's (ibid.) point gets to one of the crucial yet largely unexplained aspects of $\mathrm{Al}$ education regarding the cultural politics of knowledge. A great deal of criticism about the social uses of Al technology suggests that Al replicates biases and prejudice. Such a description, although correct about the replication of injustice, wrongly suggests a potential neutral, unbiased and objective data-production process. Virginia Eubanks's Automating Inequality (2017) and Cathy O'Neil's Weapons of Math Destruction (2016) both make this point. Eubanks (2017), for example, details how long-standing racist and classist assumptions get built into Al technology that surveils, tracks and automatically cuts social benefits to profiled recipients. While Eubanks (ibid.) and O'Neil (2016) are correct that the technology does this, they mistakenly presume that the technology could be used in a neutral and unbiased way, as if the technology could be outside of contested cultural meanings, values and ideologies. The mistake here is similar to the common false assumption that bias can be rooted out of standardized tests to arrive at culturally and politically neutral standardized tests. Data need to be comprehended as profoundly motivated representations of reality. As Stuart Hall (1997) points out, representations can never be seen as merely reflections of reality or merely a function of authorial intent. Representations produce reality and their production, circulation, economy, subjectivity-producing tendencies, and interpretations are deeply implicated in relations of power (ibid.: 15-63). The acts of framing and interpreting knowledge depend upon prior values, assumptions and ideologies that are informed by the material and symbolic interests and the social position of the one doing the framing and interpreting. Data manufacture needs to be comprehended as a signifying practice, and as a part of representational politics in which cultural producers are responsible for the meanings that they make, the ways those meanings affirm or contest existing broader public discourses and the ways those representations create subject positions for the consumers of those meanings. Contrary to Hall's (ibid.) insights, both standardized testing and the Al education applications I discussed above are premised upon the ideology of positivism, which has a long history of anti-democratic approaches to education (Giroux, 2011: 19-47; Saltman, 2020: 73-91).

The framing of knowledge as 'data' (a kind of magical product delinked from the conditions of its production) continues a long-standing positivist approach to teaching and learning. The ideology of positivism has played a central role in both the industrial and neo-liberal trends of the ways schooling has been involved in the social and cultural reproduction of capital. Positivism treats knowledge as a collection of facts and denies the theoretical assumptions that inform claims to truth (Adorno, 2000: 75). In the industrial economy, the ideology of positivism fostered a 'hidden curriculum' of capitalism in which, under the guise of liberal values for the public good and humanism, the school taught knowledge, skills, dispositions and ideologies for work (Giroux, 1983: 58-9). Tests and grades purporting to be neutral, disinterested, objective and universally valuable were involved in rewarding the class-based and cultural knowledge of professional-class students and punishing that of working-class and non-dominant students. Positivism played an important role in de-democratizing the culture of schools such that the process of teaching and learning would be depoliticized. Positivism conceals the relationships between knowledge and power, 
and through the guise of disinterested neutrality imposes the knowledge, values, dispositions and cultural capital of ruling groups and classes while punishing the knowledge, tastes and dispositions of oppressed people. Positivism presents truth as a collection of atomized facts, presents knowledge as delinked from the social world, and presents the subject as an atomic consumer of decontextualized fact. In contrast to positivism, democratic schooling would foster a culture of schooling in which knowledge is comprehended in relation to broader questions of power and politics, in which claims to truth are comprehended in relation to broader social antagonisms, and in which knowledge and learning as social products are seen as forming socially constituted selves.

\section{Conclusion}

From the early neo-liberal restructuring of education since the 1980s to the present, educational privatization has been characterized by a few key elements that continue in the advent of digital privatization, and particularly in the manifestations of Al education: (1) the use of privatization to amass wealth by suppressing teacher wages and transferring that wealth to investors; (2) the de-democratizing shift in political control over schools, curriculum and pedagogy afforded by privatization from teachers, students, parents and communities to investors and owners; (3) the pairing of privatization with standardization, homogenization of knowledge and transmissional, authoritarian models of pedagogy; (4) the repressive shift in social and cultural reproduction to pillage the public and commodify bodies; and (5) the pairing of privatization with the positivist denial of cultural politics - that is, with democratic conceptions of culture.

Despite the dominant and anti-democratic tendencies in the uses of $\mathrm{Al}$ education, there are democratic and progressive possibilities in the uses of $\mathrm{Al}$ technology. For example, the Whitney Biennial in New York in 2019 featured a video art installation, Triple-Chaser by Forensic Architecture (2019), about an Al project that was designed to teach computers to recognize tear gas grenade canisters manufactured by Safariland that were deployed against civilian populations engaged in public dissent and protest around the world. The public pedagogy of the art installation educates viewers about the for-profit activities of the arms manufacturer and its role in governments' violent attacks on civilian populations. The display shows how artists taught computers to recognize the tear gas canisters, how they recruited people around the world to submit images of canisters for computer identification and also shows video footage of the attacks by police and military. The technology enabled the artists to illuminate the relationships between the state and corporations, while showing how the hidden commodity chain can be reconstructed to expose the ways in which nation states terrorize populations, including US border agents firing tear gas at civilians in Mexico. Triple-Chaser uses Al to produce data about objects (tear gas canisters) that give new meaning to those objects' history, social location and violent use by interested parties. The investigation expanded to reveal Safariland owner Warren Kanders's financial involvement in Sierra Bullets, which were used by the Israeli Defence Forces who fired live ammunition at Palestinians in Gaza. The exhibit also highlighted its own location in relation to the subject matter by revealing that Warren Kanders was the vice-chair of the board of the Whitney Museum.

Forensic Architecture's Triple-Chaser project built on the work of numerous activist organizations that are part of a broader social movement for global justice, including Decolonize this Place. In July 2019, in reaction to the social movement 
and the art exhibit, Kanders resigned from the board of the Whitney Museum. The project illustrates the democratic educative potential of the use of Al technology as part of a broader effort between cultural producers and activists to hold economic and political elites accountable for abuses of power. It suggests the possibilities for using the technology to enable students to comprehend the relationships between learning, knowledge, the self, society and the workings of power. Critical pedagogy is a necessary element of such projects. It would allow students to theorize the technology they utilize in ways that comprehend claims to truth in relation to broader social antagonisms, and to comprehend the ways these antagonisms are subjectively experienced (Saltman, 2017, 2018). To be used in ways that accord with values for justice and democracy, Al education demands an engagement with representational politics that allows users to comprehend knowledge politically. To use Al education well requires being explicit about the ethical and political norms guiding the use and purpose of the technology, and rejecting the quasi-scientific mode of description that obscures the values, politics, interests and ideologies animating the framing of data and the use of the technology. The technology can be harnessed to democratic education projects in which the technology aids social interpretation as a means of collective agency to intervene in public problems, to challenge oppressive power and to foster democratic social relations. However, without adequately comprehending Al education as a form of cultural production and representational politics, Al education stands to continue as the newest incarnation of public sector profiteering by making state schools reliant on expensive technology that only worsens the anti-intellectual and anti-democratic tendencies of the educational reforms that preceded it.

\section{Acknowledgements}

I thank the guest editors and reviewers for their thoughtful insights and suggestions.

\section{Notes on the contributor}

Kenneth J. Saltman is Professor of Educational Policy Studies at the University of Illinois at Chicago, USA. He is the author most recently of The Swindle of Innovative Educational Finance (University of Minnesota Press, 2018) and Scripted Bodies: Corporate power, smart technologies and the undoing of public education (Routledge, 2016).

\section{References}

Adorno, T.W. (2000) Introduction to Sociology. Ed. Gödde, C. Trans. Jephcott, E. Stanford, CA: Stanford University Press.

Boninger, F., Molnar, A. and Saldaña, C.M. (2019) Personalized Learning and the Digital Privatization of Curriculum and Teaching. Boulder, CO: National Education Policy Center. Online. https://tinyurl.com/r2ul3zp (accessed 31 March 2020).

Bourdieu, P. (1986) 'The forms of capital'. In Richardson, J.G. (ed.) Handbook of Theory and Research for the Sociology of Education. Westport, CT: Greenwood Press, 241-58.

Bowles, S. and Gintis, H. (2011) Schooling in Capitalist America: Educational reform and the contradictions of economic life. Chicago: Haymarket Books.

Eubanks, V. (2017) Automating Inequality: How high-tech tools profile, police, and punish the poor. New York: St Martin's Press.

Forensic Architecture (2019) Triple-Chaser. Online. https://tinyurl.com/wj2lvmv (accessed 1 April 2020).

Giroux, H.A. (1983) Theory and Resistance in Education: A pedagogy for the opposition. South Hadley, MA: Bergin and Garvey. 
Giroux, H.A. (2011) On Critical Pedagogy. New York: Continuum.

Hall, S. (ed.) (1997) Representation: Cultural representations and signifying practices. London: SAGE Publications.

Kronk, H. (2019) 'Johns Hopkins researchers found "significant problems" with Summit Learning use in Providence schools'. e-Learning Inside News, 1 July. Online. https://tinyurl.com/rgugf3j (accessed 1 April 2020).

Manolev, J., Sullivan, A. and Slee, R. (2019) 'The datafication of discipline: ClassDojo, surveillance and a performative classroom culture'. Learning, Media and Technology, 44 (1), 36-51. https://doi.org/10.1080/17439884.2018.1558237.

Means, A.J. (2018) Learning to Save the Future: Rethinking education and work in an era of digital capitalism. New York: Routledge.

NSTC (National Science and Technology Council) Committee on Technology (2016) Preparing for the Future of Artificial Intelligence. Washington, DC: National Science and Technology Council. Online. https://tinyurl.com/h4ekpt2 (accessed 1 April 2020).

O'Neil, C. (2016) Weapons of Math Destruction: How big data increases inequality and threatens democracy. New York: Crown.

Pane, J.F. (2018) Strategies for Implementing Personalized Learning while Evidence and Resources Are Underdeveloped. Santa Monica, CA: RAND Corporation.

Roberts-Mahoney, H., Means, A.J. and Garrison, M.J. (2016) 'Netflixing human capital development: Personalized learning technology and the corporatization of K-12 education'. Journal of Education Policy, 31 (4), 405-20. https://doi.org/10.1080/02680939.2015.1132774.

Sadowski, J. (2019) 'When data is capital: Datafication, accumulation, and extraction'. Big Data and Society, January-June, 1-12. Online. https://tinyurl.com/trbgamb (accessed 31 March 2020). https://doi.org/10.1177/2053951718820549.

Saltman, K.J. (2010) The Gift of Education: Public education and venture philanthropy. New York: Palgrave Macmillan.

Saltman, K.J. (2017) Scripted Bodies: Corporate power, smart technologies, and the undoing of public education. New York: Routledge.

Saltman, K.J. (2018) The Swindle of Innovative Educational Finance. Minneapolis: University of Minnesota Press. https://doi.org/10.5749/9781452962047.

Saltman, K.J. (2020) 'Antitheory, positivism, and critical pedagogy'. In Di Leo, J.R. (ed.) What's Wrong with Antitheory? London: Bloomsbury Academic, 73-91.

Selwyn, N. (2019) Should Robots Replace Teachers? Al and the future of education. Cambridge: Polity Press.

Singer, N. (2017) 'The Silicon Valley billionaires remaking America's schools'. New York Times, 6 June. Online. https://tinyurl.com/y9hyjygw (accessed 31 March 2020).

Smythe, D.W. (1981) 'On the audience commodity and its work'. In Smythe, D.W. Dependency Road: Communications, capitalism, consciousness, and Canada. Norwood, NJ: Ablex, 22-51.

Williamson, B. and Piattoeva, N. (2019) 'Objectivity as standardization in data-scientific education policy, technology and governance'. Learning, Media and Technology, 44 (1), 64-76. https://doi.org/10.1080/17439884.2018.1556215.

Williamson, B., Pykett, J. and Nemorin, S. (2018) 'Biosocial spaces and neurocomputational governance: Brain-based and brain-targeted technologies in education'. Discourse: Studies in the Cultural Politics of Education, 39 (2), 258-75. https://doi.org/10.1080/01596306.2018.1394421.

Wrench in the Gears (2019) '3rd grade reading guarantees: Impact investors build system to terrorize eight year olds'. Wrench in the Gears, 27 February. Online. https://tinyurl.com/yxfs85vz (accessed 31 March 2020).

Žižek, S. (2018) Like a Thief in Broad Daylight: Power in the era of post-human capitalism. London: Allen Lane.

Zuboff, S. (2019) The Age of Surveillance Capitalism: The fight for a human future at the new frontier of power. New York: Public Affairs. 